Revista Iberoamericana, Vol. LXXIII, Núm. 220, Julio-Septiembre 2007, 615-630

\title{
INTELECTUALES PÚBLICOS INDÍGENAS EN AMÉRICA LATINA: UNA APROXIMACIÓN COMPARATIVA
}

\author{
POR \\ JOANNE RAPPAPORT \\ Georgetown University
}

En los países andinos del nuevo milenio es imposible considerar cuestiones tales como la reforma constitucional, el desarrollo sostenible, los derechos humanos o la democracia participativa sin referirse a una capa creciente de intelectuales indígenas quienes, en busca de nuevos modelos para la sociedad civil, experimentan con modos nativos y occidentales de conocimiento con el fin de fortalecer las reivindicaciones étnicas a los niveles regional y nacional. ${ }^{1}$ Además de su contribución como activistas, este nuevo sector dentro de la sociedad indígena está tomando parte en los diálogos étnicos a través de la publicación de sus propias investigaciones sobre aspectos de la sociedad nativa y su relación con la sociedad dominante, frecuentemente dentro de los campos de la antropología y la historia.

Quiero reflexionar sobre el surgimiento de esta nueva voz indígena en cuatro países andinos: Colombia, Ecuador, Perú y Bolivia, partiendo de una serie de discusiones que tuvieron lugar en 1995 con estudiantes indígenas de antropología de la Facultad Latinoamericana de Ciencias Sociales en Quito, Ecuador: Marcelo Fernández, Margarita Huayhua, Esteban Ticona y Luis de la Torre, todos los cuales son miembros de la intelectualidad nativa de sus países. A lo largo de tres meses, intentamos construir un perfil de los nuevos intelectuales indígenas de los Andes. Nos detuvimos en la historia del proceso educativo para comprender la relación que mantiene este sector con la alfabetización y con la oralidad. Comparando las varias experiencias de los miembros del grupo, tratamos

\footnotetext{
${ }^{1}$ Quiero agradecer a varias personas que han contribuido con sus comentarios a la formación de mis ideas: Catherine Allen, Graciela Bolaños, Quetzil Castañeda, Marisol de la Cadena, Luis Alberto Escobar, Paul Gootenberg, Kevin Healey, Jorge León, Florencia Mallon, Mauricio Parada, Abelardo Ramos, Inocencio Ramos, Carol Smith, Kay Warren y José Yánez del Pozo. Mis agradecimientos especiales van a Luis de la Torre, Marcelo Fernández, Margarita Huayhua y Esteban Ticona Alejo, cuyas reflexiones sirvieron de base para este ensayo, aunque saqué mis propias conclusiones del diálogo que tuvimos, y a los miembros de nuestro equipo colaborador, Myriam Amparo Espinosa, David Gow, Adonías Perdomo, Susana Piñacué y Tulio Rojas Curieux. Mis investigaciones etnográficas sobre los intelectuales indígenas colombianos han sido financiadas por una beca otorgada al Instituto Colombiano de Antropología por Colciencias (1996-97), la escuela de posgrado de Georgetown University (1998-1999) y una beca de colaboración internacional de la Wenner Gren Foundation for Anthropological Research (1999-2002).
} 
de establecer cuáles son los diferentes contextos en los que la intelectualidad indígena se ha multiplicado en décadas recientes. Finalmente, bregamos con el problema del carácter y los contenidos de formas literarias descolonizadas creadas por los intelectuales nativos dentro de los contextos sociopolíticos de los cuatro países. ${ }^{2}$

\section{HACIA UNA TIPOLOGÍA DE LOS INTELECTUALES INDÍGENAS}

A lo largo de los Andes ha surgido una intelectualidad indígena bajo una constelación común de condiciones (cf. Healey). Entre ellas, el retorno de la democracia liberal y el surgimiento de movimientos étnicos han proveído escenarios en los que la intelectualidad indígena ha encontrado su voz, ha identificado a sus públicos y ha participado en la acción política (Gros Políticas; Nelson; Ticona; Van Cott; Warren; Yashar). La proliferación de las organizaciones no gubernamentales con financiamiento externo (Farrington, Bebbington, Wellard y Lewis) y los nuevos movimientos sociales (Alvarez, Dagnino y Escobar; Escobar y Alvarez), han facilitado a estos pensadores nativos los fondos necesarios y el espacio institucional para la investigación, la redacción, y la publicación. La extensión de la educación secundaria y superior a los campesinos e indígenas ha posibilitado el entrenamiento de los estudiosos y pensadores nativos (Luykx). La expansión de la educación de adultos y el crecimiento de canales electrónicos de comunicación controlados por sectores indígenas (Camacho) han creado las condiciones para un diálogo dentro del sector intelectual nativo, entre los intelectuales nativos y los metropolitanos, y con las comunidades indígenas. Finalmente, el quinto centenario de la invasión de las Américas ha provisto un catalizador y un espacio de reflexión por los escritores y políticos nativos (Nelson).

En el grupo de discusión intentamos definir los contornos de esta intelectualidad indígena, limitándonos a los que se podría llamar los “intelectuales orgánicos” del movimiento nativo, que funcionan a nivel regional y nacional en representación de un sector étnico emergente, en contraste con los “intelectuales tradicionales”, que siempre han servido como autoridades locales o como intermediarios entre la comunidad y la sociedad dominante (Feierman; Gramsci). Es decir, trazamos una distinción entre las nuevas autoridades comunitarias, los líderes de organizaciones y los profesores bilingües por un lado, y los políticos tradicionales, los antiguos maestros de escuela y los tinterillos por el otro, siendo los segundos portadores de una ideología del Estado y los primeros forjadores de una nueva ideología étnica. ${ }^{3}$ También los distinguimos de los "sabedores" nativos -los chamanes, los curanderos, los memoristas (o historiadores orales de las

\footnotetext{
${ }^{2}$ Mis reflexiones en torno a los intelectuales públicos indígenas colombianos surgen del trabajo etnográfico que desde 1996 estoy realizando en el sudoccidente del país, una investigación marcada por su carácter colaborativo entre investigadores indígenas, nacionales e internacionales (Rappaport 2005a, 2005b).

3 Reconocemos, sin embargo, que estas dos categorías son fluidas, que algunos miembros de la intelectualidad tradicional han logrado transformarse en intelectuales orgánicos del movimiento indígena y que la intelectualidad actual se nutre, en parte, de los conocimientos de los intelectuales tradicionales.
} 
comunidades)- cuya producción intelectual está más que todo dirigida a una población interna y no a un público metropolitano, a pesar de que reconocemos sus significativos aportes a la conformación del discurso de los nuevos intelectuales orgánicos. ${ }^{4}$

El sector al que nos dirigimos funciona dentro de lo que Mary Louise Pratt llama "la zona del contacto", "los espacios sociales en los cuales las culturas se encuentran, se chocan, y se agarran en contextos de relaciones de poder asimétricas” (34). Como consecuencia, mientras los "sabedores" de las comunidades emplean formas autóctonas de expresión dirigidas a un público interno y los intelectuales tradicionales se centran en formas nacionales de expresión, estos nuevos intelectuales orgánicos se apropian selectivamente del idioma de la metrópoli, “....infiltrándolo en varios grados con idiomas indígenas para crear autorrepresentaciones orientadas tanto hacia los públicos metropolitanos como hacia las comunidades mismas" (35; cf. Beverley). Este intento ha sido descrito por Marcelo Fernández, antropólogo aymara y participante en el grupo de discusión:

Una de nuetras misiones es precisamente facilitar instrumentos políticos, sociales, ideológicos y culturales del mundo criollo, de hacer ver que estas estructuras no son estructuras compactas, sino que son constructos de fragmentos, que es posible revertir o apropiar de elementos consistentes.

Para estos nuevos intelectuales, existe una distinción entre dos culturas igualmente válidas -la cultura indígena y la metropolitana-, perspectiva que les lleva a enmarcar lo indígena dentro de un espacio occidental (Lomnitz-Adler 237; cf. Jackson).

Pero tal vez sea demasiado simplista esta caracterización de un pensamiento indígena que surge de un contexto cultural altamente polarizado. Ignora los intentos de crear un discurso indígena moderno sobre la base de un proceso de hibridación de varios siglos. Igualmente, desconoce toda una trayectoria histórica del empleo indígena de discursos metropolitanos dentro de géneros europeos de expresión, como son los expedientes legales y la expresión visual colonial (Adorno; Gruzinski; Rappaport, The Politics). Tanto Lomnitz como Pratt consideran que, al valerse de la escritura, los intelectuales indígenas se apropian de espacios discursivos europeos. Tal vez sea cierto para el momento de contacto, pero a lo largo de los siglos, prácticas tan occidentales como la lectoescritura se han transformado en formas culturales entrelazadas (Thomas), cuyo proceso de

\footnotetext{
${ }^{4}$ Agradezco a Myriam Amparo Espinosa por el término de "sabedores”, que permite una distinción entre los intelectuales tradicionales en las localidades rurales y los especialistas tradicionales nativos. Debo mencionar aquí que algunos sabedores han logrado transformarse en intelectuales orgánicos. Los mejores ejemplos son el cuerpo de médicos nativos de la etnia nasa, quienes, a raíz de una avalancha que destruyó su territorio en 1994, han logrado participar como intelectuales en la conformación de un nuevo territorio en los sitios de reasentamiento, obrando como especialistas en las organizaciones oficiales y locales encargadas de la tarea de reubicación de las poblaciones y reconstrucción de sus economías (Rappaport y Gow 1997); algunos médicos tradicionales nasas que ejercen la profesión de maestros bilingües después de recibir una formación universitaria y el historiador comunitario de Guambía, Avelino Dagua, quien ha ejercido una influencia profunda en el Comité de Historia del Pueblo Guambiano (Dagua, Aranda y Vasco; Vasco, Dagua y Aranda).
} 
interconexión es mucho más interesante que sus orígenes en dos campos supuestamente primordiales. Es decir: el proceso histórico termina borrando una distinción entre dos primordialidades, “indígena” y “metropolitano”, creando en cambio, dos posicionamientos políticos que comparten muchos referentes y prácticas culturales. Así plantean los intelectuales indígenas, como demuestra la pequeña explicación que el Taller de Historia Oral Andina -instituto de investigación aymara- agrega a la página de copyright de sus publicaciones en Ediciones Aruwiyiri:

Aruwiyiri: lit.=El que incendia la voz. Nombre de un boletín que publicaba la "Gran Liga Internacional de Cultura Indígena” dirigida por el preceptor Felipe Pizarro en la década de 1910. Nuestra editorial ha querido rescatar ese esfuerzo para simbolizar la incorporación de la palabra escrita en el tronco de los saberes ancestrales de nuestras comunidades.

Para los integrantes del THOA, la lectoescritura es un "saber ancestral" que no se puede distinguir como exclusivamente “europeo”, sino que es igualmente "aymara”. En este sentido, es útil considerar la metodología de estos intelectuales no como una apropiación de prácticas ajenas, sino como el ejercicio intercultural, con la interculturalidad entendida como, "partir desde el conocimiento de lo propio para ir integrando otros conocimientos” (CRIC, "Elaboración...” 4), enfatizando que "lo propio" no es un conjunto primordial de costumbres, sino una posición dentro de la sociedad moderna. La interculturalidad presupone más que una práctica intelectual, ya que es una aproximación política al conocimiento que encuentra sus raíces en: "Las relaciones generadas y vivenciadas desde la valoración y respeto por el otro, en la búsqueda de condiciones de igualdad desde las diferencias" (CRIC, “Informe...” 2). Es decir, es más que la aceptación de la diversidad cultural, ya que implica la creación de relaciones horizontales entre sectores culturalmente diferentes de una sola sociedad.

El carácter de estos intelectuales es, entonces, altamente político. No sólo estamos hablando de intelectuales públicos en el sentido de "escritores y pensadores que se dirigen a un público general y educado” (Jacoby 5), sino que tenemos que reconocer que obran con un enfoque étnico; son activistas. Foucault habla de los “intelectuales específicos”, cuyo poder proviene de un cuerpo específico de conocimiento. En este caso, tal conocimiento está siendo puesto al servicio de un movimiento social. Para usar la tipología de Claudio Lomnitz-Adler, el grupo que nos concierne cumple con funciones internas y de articulación, sintetizando culturas locales y articulando con grupos externos, empleando un discurso específico ligado a una lucha, ambos dirigidos a toda una gama de públicos, tanto locales como nacionales. Por lo tanto, aun cuando sean intelectuales públicos y específicos, preferimos caracterizarlos como intelectuales indígenas, tanto para subrayar la pertenencia étnica que los define como intelectuales, como para enfatizar su carácter moderno y metropolitano.

Es importante reconocer que los intelectuales indígenas pertenecen al sector de los intelectuales orgánicos, y que no son estrictamente subalternos. Siguiendo a Spivak (289), las construcciones culturales subalternas que los nutren han sido transformadas dentro de la arena de la militancia; así trascienden a su subalternidad: 
Frecuentemente los extraordinarios intelectuales orgánicos... que llegan a ser voceros de la subalternidad son recibidos como subalternos representativos. Esta recepción es un rasgo de nuestro deseo de fijarnos en los individuos. Los esfuerzos de estas figuras singulares que se transforman en intelectuales orgánicos son desechos al posicionarlos como "los" subalternos (292).

Es decir: son actores empoderados dentro de una realidad más amplia que sus comunidades. Sin embargo, es central a la misión del intelectual indígena su pertenencia étnica. No son simplemente intelectuales de orígenes nativos, sino pensadores cuyo discurso surge de su identidad étnica, de su conciencia de ser diferentes. En este sentido, no es la subalternidad lo que los distingue, sino la diferencia, noción articulada dentro de un conjunto común de valores y preceptos que emanan de las luchas por la identidad y la ciudadanía propias del movimiento indígena latinoamericano. Es decir, para este sector, los ejes fundamentales de su discurso se centran en la etnicidad, la interculturalidad y el diálogo interétnico. Sea plasmado en la descripción etnográfica, la narración histórica, la retórica política, el argumento legal o el proyecto de desarrollo comunitario, el discurso de los intelectuales indígenas está encaminado hacia la realización de los proyectos de un movimiento político que busca la participación en un Estado pluriétnico o plurinacional (Ramón). Esto no quiere decir que todos los intelectuales indígenas sean militantes del movimiento étnico, sino que su producción intelectual nutre y se nutre de las ideas y reivindicaciones de las organizaciones.

LA PRODUCCIÓN INTELECTUAL INDÍGENA

Es amplia la gama de géneros en los que escriben estos intelectuales étnicos. Va desde la etnografía descriptiva basada en la escritura antropológica tradicional (Berichá; Dagua, Aranda y Vasco; Fernández) y la historia nutrida tanto por los géneros de historias escritas por académicos y por intelectuales tradicionales de las localidades (Choque, Soria, Mamani, Ticona y Conde; Inda; Mamani), a los análisis socioeconómicos de las realidades económicas (Cabildo, Taitas y Comisión de Trabajo del Pueblo Guambiano; Comunidad Camëntsá) modelados en el discurso desarrollista (Escobar 41; Gow), la investigación etnolingüística por hablantes nativos de los idiomas indígenas (Muelas; Yule), el análisis sintético de los proyectos nacionales de los movimientos indígenas nutrido por la ciencia política (Ari; Macas; Pacari; Ticona; Ticona, Rojas y Albó) y finalmente, la obra periodística escrita en idiomas indígenas o en castellano para un público nacional (Archer y Costello).

Muchos de estos autores escriben para un público metropolitano educado, produciendo obras publicadas por editoriales urbanas que circularn entre intelectuales nacionales, haciéndolos intelectuales públicos en el mejor sentido de la palabra (Beverley). Sin embargo, preparan materiales más asequibles, frecuentemente en idiomas nativos, usando los medios impresos y electrónicos para llegar a las poblaciones rurales (Andean Oral History Workshop). En estos casos, los autores están ligados a organizaciones no gubernamentales, como el Taller de Historia Oral Andina (THOA) en Bolivia, que hacen posible tanto la investigación y publicación académica como la diseminación de materiales 
destinados a las comunidades. Otros intelectuales, que en Colombia por lo menos son la mayoría de los intelectuales indígenas, dirigen programas de educación bilingüe, produciendo cartillas y evaluaciones de programas educativos (CRIC; Molina, Aranda y Tunubalá) dentro del marco de las organizaciones étnicas. El mejor ejemplo es el Programa de Educación Bilingüe del Consejo Regional Indígena del Cauca (CRIC), cuyo objetivo es la creación de una ciudadanía que se identifique como indígena y que asuma posiciones críticas frente a las propuestas del gobierno, una ciudadanía étnica capaz de generar pautas culturales para asegurar la supervivencia de la colectividad frente a la globalización y la creciente influencia de la cultura dominante colombiana. ${ }^{5}$ Es decir, aunque esta propuesta se ubique en el plano educativo e incluya un proyecto curricular y el entrenamiento de maestros, persigue más bien un objetivo encaminado a crear escuelas como ejes de organización local y productores de dirigentes comunitarios, no como planteles dedicados exclusivamente al entrenamiento académico de los niños. Mediante la difusión popular de publicaciones y la creación de escuelas como ejes organizativos, lo que logran THOA y CRIC es la creación de una “esfera contrapública indígena”, donde "se formulan y se expresan conocimientos alternativos, de esta forma se legitima el derecho, tanto cultural como político, a la diferencia” (Stephenson 101).

La mayor parte del cuerpo de escritos y contribuciones intelectuales de este sector ha sido producida por autores indígenas trabajando solos o con coautores nativos; sin embargo, existen intentos de una colaboración muy fructífera entre intelectuales metropolitanos y sus contrapartes indígenas (Vasco, Dagua y Aranda) e intelectuales extranjeros con autores nativos (Arnold, Jiménez y Yapita). En estos casos, los objetivos y metáforas alrededor de los cuales se construye el discurso provienen de un pensamiento nativo, y con frecuencia el lector puede distinguir entre las voces de los diferentes autores, como es el caso de la historia guambiana, en la cual se puede distinguir entre las voces de los jóvenes intelectuales indígenas, el historiador tradicional guambiano y el antropólogo bogotano, aunque tales voces no están no explícitamente marcadas (Vasco, Dagua y Aranda; cf. Rappaport, “Redrawing...”).

Pero no es solamente la temática o el proceso de redacción y diseminación lo que diferencia a estas obras, sino que a veces sus autores intentan experimentar con nuevos géneros de expresión y con una nueva teorización proveniente de ideas y metáforas autóctonas. Por ejemplo, se apropian de géneros experimentales latinoamericanos, como el relato testimonial, transformándolo en un diálogo entre indígenas. De esta manera se redefine el quehacer editorial del testimonio, al ponerlo en manos del que es miembro de la misma cultura como el informante. En el caso de El escribano de los Caciques Apoderados (Condori y Ticona), testimonio de un integrante del movimiento indígena boliviano de la década de los treinta que buscaba recuperar títulos coloniales para restablecer las jerarquías autóctonas del poder (cf. Rivera Cusicanqui), el trabajo de edición por un académico aymara dejó intactas las formas narrativas nativas, a diferencia de la abrumadora mayoría de los ejemplos de literatura testimonial, cuyo proceso de edición borra la narratividad propia. De igual modo, hay intentos de intelectuales

\footnotetext{
${ }^{5}$ Para una apreciación de los logros del programa por parte de los mismos protagonistas, véanse Bolaños y Sisco; Bolaños y Strack; Ramos et. al.
} 
indígenas de base de crear cartillas educativas que integran categorías nativas como los ejes organizativos de sus obras. El mejor ejemplo es una historia de la comunidad aymara de Cohana, escrito por el educador local Alejandro Mamani, que a pesar de estar redactado en la forma superficialmente occidental de tiras cómicas, logra, a través de una distinción gráfica entre diferentes tipos de datos recolectados, distinguir entre diferentes categorías de conocimiento de acuerdo con una epistemología aymara (Rappaport, "Hacia la construcción...”).

Uno de los objetivos de los lingüistas indígenas colombianos es la conformación de un nuevo vocabulario en los idiomas nativos para poder expresar palabras y conceptos que se originan en la tecnología y la organización social modernas. Pero esa tarea es más que la simple creación de neologismos en lenguas indígenas. Quizá más innovador sea el uso de la traducción como metodología para el análisis social y epistemológico. Esta metodología surgió de la experiencia de traducir la Constitución colombiana de 1991 al nasa yuwe, un idioma nativo del suroccidente colombiano (Ramos y Cabildo de Mosoco). Por un lado, como me informó su traductor, se intentó crear una traducción de los artículos de la Constitución que reflejara tanto las prioridades políticas nasas y sus significados culturales como el sentido del documento original escrito en castellano (cf. Rojas Curieux). Por otro lado, el hecho de reconceptualizar desde el pensamiento nasa los conceptos fundacionales de la Constitución (tales como "autonomía”, "autoridad”, “Estado”, “Estado de derecho”, “soberanía” y la misma noción de “nación”) planteó la necesidad de abrir caminos en pos de la creación de una nueva nación multicultural que acepte la heterogeneidad, no sólo en cuanto a la representación electoral y los cargos administrativos, sino en el proceso mismo de redefinir qué es un "Estado-nación”.

La crítica de cine Rey Chow plantea que la traducción no es solamente un movimiento unidireccional desde una lengua original a otra menos auténtica (en el sentido de no ser el idioma en el cual se escribió el texto), sino un movimiento en que se confunden las prioridades lingüísticas. Una traducción está escrita en la lengua nativa del traductor. En este sentido, “'lo nativo’ es el punto ‘original’ de referencia” (189). Es decir, traducir es más bien traficar entre idiomas que son igualmente “originales” (183). Chow propone que traducir es el acto de suplementar lo que dice el "original” (186), liberándolo de sus limitaciones originales. Esto es precisamente lo que buscaron los traductores nasas de la Constitución y que los llevó a una nueva metodología analítica basada en la traducción. Desde esa época, los educadores nasas -quienes estudian en programas universitarios coordinados por sus organizaciones étnicas-se apropian de conceptos teóricos occidentales mediante su traducción al nasa yuwe, de tal forma que nociones como "cultura”, "sistema educativo", "interculturalidad” o “desarrollo" se vuelven operativas desde su reconceptualización en lengua nasa, desfamiliarizándolas así de sus referentes occidentales (Rappaport, “El espacio...”). Este es un primer intento de desarrollar marcos teóricos nativos para analizar la realidad (Rafael), lo que demuestra que las dudas de algunos teóricos acerca de la posibilidad del ejercicio de una voz intelectual subalterna en campos investigativos metropolitanos no tienen fundamentos. ${ }^{6}$

\footnotetext{
${ }^{6}$ Por ejemplo, Partha Chatterjee (17) cuestiona si en una etnografía hecha por un antropólogo subalterno estarían invertidas las relaciones de sujeto-objecto, de occidental y no-occidental. Se
} 
EL SURGIMIENTO DEL INTELECTUAL INDÍGENA ANDINO: UNA MIRADA COMPARATIVA

Los ejemplos empleados aquí provienen de Bolivia, Colombia, y en menor grado, del Ecuador, casos que presentan similitudes muy claras en cuanto al surgimiento de los intelectuales indígenas, con los contextos históricos comunes que ya he mencionado. Sin embargo, hay diferencias significativas entre la producción intelectual de los pensadores nativos de los tres países, divergencias que se originan en las diferentes historias vividas por los nativos de estos Estado-naciones. A un nivel, existe una clara diferenciación entre el peso y volumen de la obra de los intelectuales indígenas bolivianos, en contraste con las contribuciones más recientes y ocasionales de Colombia y Ecuador. También existen divergencias entre los géneros y lenguajes de los intelectuales de los tres países y entre sus posicionamientos dentro del campo político.

Los miembros no bolivianos del grupo de discusión se fijaron en la historia larga de escritura indígena en Bolivia, y en el número de ONG con dirección y filosofía indígenas dedicadas a la investigación y a la creación de una intelectualidad indígena nacional. En contraste, en Colombia y en Ecuador, la producción intelectual indígena es más incipiente, y frecuentemente depende de la buena voluntad de ONG no nativas y de sus aliados académicos metropolitanos para la publicación y la difusión de sus obras. Tales diferencias se originan en dos factores que distinguen a Bolivia por un lado, de Colombia y Ecuador por el otro.

Primero, desde la época colonial, siempre ha vivido una población significativa de indígenas en las ciudades bolivianas, posibilitando la opción de ser nativo y urbano a la vez; de hecho, muchos dirigentes políticos nativos, quienes integran el cuerpo de intelectuales indígenas bolivianos, nacieron y se criaron en contextos urbanos (Ticona, Rojas y Albó). En contraste, la migración indígena a las ciudades ecuatorianas sólo ha logrado números significantes en décadas recientes y bajo formas de urbanización del siglo xx, imposibilitando la retención de formas indígenas de identidad en los barrios obreros y marginales. Los migrantes urbanos en Colombia, en contraste con Bolivia y Ecuador, cuando tienen origen indígena son desindianizados antes de llegar a la ciudad, impidiendo el florecimiento de una cultura indígena urbana. ${ }^{7}$ Mientras los intelectuales indígenas colombianos y ecuatorianos viven en medios urbanos, su llegada a las ciudades ha sido motivada por la búsqueda de oportunidades educativas y la participación en la

pregunta si esa etnografía subalterna seguiría las mismas convenciones literarias que una etnografía occidental. Concluye que "existe una relación de poder involucrada en la mera concepción de la autonomía de las culturas”, hecho que impediría el surgimiento de una autoetnografía más autónoma. Sin embargo, los análisis indígenas latinoamericanos abarcan las problemáticas de la sociedad dominante, y son así un especie de "antropología indígena de los blancos”, aunque a veces asumen formas de representación novedosas y diferentes a aquellas de la sociedad dominante. Es precisamente el hecho de haberse enfrentado a las relaciones de poder a través de la política étnica lo que posibilita este tipo de discurso indígena en Latinoamérica.

${ }^{7}$ Algunas excepciones importantes son la aparición de círculos interétnicos indígenas entre estudiantes universitarios, en las cárceles, y en el movimiento armado (Espinosa), y la creación de cabildos indígenas urbanos (cf. Dover). 
dirección de organizaciones indígenas o en ONG's, en contraste con las masas de migrantes que llegan a las ciudades en busca de empleo. Por lo tanto, aun cuando la intelectualidad nativa de los tres países escribe desde la ciudad, sus lazos con las áreas urbanas son diferentes de un país a otro.

Por otro lado, la revolución de 1952 posibilitó la educación nativa y el surgimiento temprano de un movimiento sindicalista en la industria minera dio luz a la organización política étnica en épocas más tempranas que el movimiento campesino colombiano, de cuyo seno surgió el movimiento indígena (Zamosc), o el movimiento de educación bilingüe en el Ecuador, que contribuyó a los cuadros de las organizaciones étnicas (León). En Colombia y Ecuador, los profesionales indígenas y los activistas nativos son el producto de las últimas dos décadas, mientras que en Bolivia, se nutren de una historia larga de educación tanto oficial como clandestina ${ }^{8}$ y de la participación en una ideología sindicalista muy sofisticada. Por lo tanto, la producción intelectual indígena ha sido más esporádica y reciente en Colombia y Ecuador que en Bolivia. La posibilidad de actuar como intelectual indígena en el escenario nacional sólo se realiza en estos dos primeros países con la creación de la CONAIE en el Ecuador y del CRIC, la ONIC, y AICO en Colombia, y con la entrada de estas organizaciones en un diálogo nacional con el Levantamiento Indígena de 1991 en el Ecuador (León; Macas; Pacari) y la participación indígena en la Asamblea Constituyente colombiana en el mismo año (Correa Rubio; Gros “Derechos...”). Como consecuencia, en Bolivia, existe un cuerpo de obras de autores indígenas que cobra una naturaleza más académica, mientras que en Colombia y Ecuador la abrumadora mayoría de las publicaciones nativas son políticas o están ligadas a misiones desarrollistas. Se debe al hecho de que existen más intelectuales nativos egresados de la universidad en Bolivia, quienes se identifican expresamente como intelectuales, mientras que los intelectuales indígenas ecuatorianos y colombianos han recibido su formación investigativa más que todo en el movimiento étnico y frecuentemente rechazan la apelación de "intelectual” por considerarla demasiado elitista.

La existencia del aymara y quechua como idiomas mayoritarios o casi mayoritarios en Bolivia y Ecuador, respectivamente, y los éxitos de campañas de alfabetización en estos idiomas, especialmente en Bolivia, significa que, dada la presencia de financiación y de oportunidades educativas, es posible publicar en idiomas nativos (Archer y Costello; Condori y Ticona; Cotacachi y Moya; Kowii) y de empezar a crear una capa de lectores indígenas. En Colombia, en comparación, donde hay una escasez de publicación en lenguas indígenas más allá de cartillas escolares y la reciente traducción de la Constitución de 1991 a varios idiomas nativos, el número reducido de hablantes de cada idioma y la carencia de una lingua franca indígena que interconecte lingüísticamente a las varias etnias colombianas ha resultado en la producción de “literaturas menores” por intelectuales indígenas colombianos, la escritura por minorías étnicas en el idioma de la mayoría de la

\footnotetext{
${ }^{8}$ En los años veinte y treinta, ante la supresión de escuelas indígenas, se crearon escuelas clandestinas en el campo boliviano, manteniendo una tradición de alfabetización indígena bajo condiciones represivas. Es significativo que los historiadores indígenas actuales se hayan fijado en el tema de la educación clandestina (Choque, Soria, Mamani, Ticona y Conde), a diferencia de los historiadores metropolitanos, que se concentran en temas diferentes.
} 
población (Deleuze y Guattari). Muchas comunidades, además, no han logrado un consenso sobre alfabetos unificados para sus idiomas, forzándolos a aplazar la producción escrita en idiomas nativos. Sin embargo, es importante notar aquí que la proporción de población indígena de cada país no influye en ningún grado en el surgimiento de una intelectualidad nativa. Mientras Bolivia y Ecuador tienen grandes poblaciones indígenas que, respectivamente, sobrepasan o se acercan a la mitad de la población nacional, en Colombia menos del dos por ciento de la población se identifica como indígena. La historia de la educación indígena y de las organizaciones nativas en cada país, tanto como las varias razones por las que las diferentes sociedades dominantes han abrazado o rechazado las reivindicaciones indígenas, cobran un valor explicativo mucho más grande que el tamaño de la población nativa para la evaluación del surgimiento de este sector intelectual.

En contraste con Colombia, Ecuador y Bolivia, existen pocos intelectuales orgánicos indígenas en la sierra peruana, a pesar de la existencia de varios intelectuales metropolitanos cuyos orígenes son nativos. El sector indígena ha tenido que enfrentarse con la existencia de una vasta intelectualidad no nativa en Lima y las provincias, la cual ha inhibido la creación de un sector intelectual nativo con sus propias aspiraciones y formas expresivas. Pero no es solamente la hegemonía de los intelectuales no indígenas la que cohíbe el surgimiento de intelectuales étnicos en el Perú: la fuerza del discurso clasista de los intelectuales izquierdistas amortigua las aspiraciones de los intelectuales de origen nativo de realizarse dentro de marcos étnicos, mientras que los indigenistas roban su voz. En el Cusco, por ejemplo, el paternalismo histórico de los indigenistas metropolitanos y la concentración de neoindigenistas en las poblaciones cholas urbanas, en conjunción con el rechazo de una operativización política de la identidad indígena en la ciudad llevan a la intelectualidad a caracterizarse como "indios mestizos", con metas exclusivamente culturales, a diferencia de la politización de los otros países andinos (de la Cadena). En Colombia, en contraste, la debilidad de los intelectuales metropolitanos, la apertura política que emanó del proceso constitucional y la falta de un indigenismo tradicional tan arraigado, dejaron un espacio para el desarrollo de intelectuales indígenas y campesinos (Rojas). En el caso ecuatoriano, la diferenciación social, cultural, y económica entre costa y sierra posibilitó la creación de un ambiente de negociación en que la sociedad mayor tolera la introducción del discurso étnico y, como consecuencia, el surgimiento de intelectuales nativos (León).

Es de igual importancia la geografía intelectual peruana en la explicación de la falta de intelectuales nativos. Mientras en el Ecuador existen tres centros intelectuales -Quito y Cuenca en la sierra y Guayaquil en la costa-, y en Colombia hay múltiples centros intelectuales en las varias ciudades grandes y medianas a lo largo del país, la centralidad de Lima en la conformación de un discurso intelectual nacional influye en la carencia de corrientes intelectuales indígenas en provincia. Según Florencia Mallon (16), la represión que arrasó con la rebelión de Tupac Amaru a finales del siglo xviII acabó con los sectores intelectuales indígenas. A partir de las luchas por la independencia, los conflictos por el poder se concentraban en la costa y en Lima específicamente, diluyendo las posibilidades de alianzas intelectuales entre capital y provincia (16). A principios del siglo, el sistema 
de sufragio limitó la participación política a las élites regionales organizadas en un sistema de dominación fragmentada étnica y regionalmente, inhibiendo el ejercicio de una voz popular que hubiera podido transformarse luego en una voz intelectual indígena. ${ }^{9}$

\section{ConcLusión}

Ha argüido recientemente Steven Feierman que cuando empezamos a estudiar el discurso de los intelectuales campesinos tenemos que romper con las nociones tradicionales de la cultura como ente homogéneo y discreto. En cambio, tenemos que investigar las vías por las cuales se comparten los discursos y se los transmiten entre culturas dentro de contextos históricos específicos. El desarrollo de intelectualidades nativos en los Andes nos lleva a la misma conclusión: que es posible continuar enfocándonos en los pueblos nativos sin ignorar las llamadas a la contextualización histórica, los procesos nacionales y globales, la atención a la complejidad y la heterogeneidad de las formaciones sociales modernas. Es decir: hay múltiples formas de ser indígena en los Andes de fin del milenio, que tenemos que reconocer e investigar, dejando de lado nuestros prejuicios frente a las manifestaciones modernas e híbridas de la indianidad. Es más, ahora, cuando aquellos que siempre han sido los objetos de nuestras investigaciones pueden compartir el diálogo, volverse interlocutores, es nuestra obligación entrar en esta conversación y no abandonarlos por públicos menos críticos o cuestionantes.

BiBLIOGRAFÍA

Adorno, Rolena. Guaman Poma: Writing and Resistance in Colonial Peru. Austin: University of Texas Press, 1986.

Alvarez, Sonia, Evelina Dagnino y Arturo Escobar, eds. Cultures of Politics, Politics of Cultures: Re-visioning Latin American Social Movements. Boulder: Westview, 1998.

Andean Oral History Workshop (Taller de Historia Oral Andina/THOA). “The Indian Santos Marka T'ula, Chief of the Ayllus of Qallapa and General Representative of the Indian Communities of Bolivia”. History Workshop Journal 34 (1992): 101-118.

Archer, David y Patrick Costello. Literacy and Power: The Latin American Battleground. Londres: Earthscan Publications, 1990.

Ari Chachaki, Waskar, ed. Aruskipasipxañasataki: el siglo XXI y el futuro del pueblo aymara. La Paz: Editorial Amuyañataki, 2001.

Arnold, Denise, Domingo Jiménez Aruquipa y Juan de Dios Yapita. Hacia un orden andino de las cosas: tres pistas de los Andes meridionales. La Paz: Hisbol/ILCA, 1992.

Berichá. Tengo los pies en la cabeza. Bogotá: Los Cuatro Elementos, 1992.

Beverley, John. Against Literature. Minneapolis: University of Minnesota Press, 1993.

\footnotetext{
${ }^{9}$ Pajuelo ennumera las diferentes razones por las cuales no ha surgido un movimiento indígena en la sierra peruana, lo que hubiera posibilitado la aparición de intelectuales públicos indígenas.
} 
Bolaños, Graciela y Peter Strack. “Parientes del Cauca: Entrevista con Graciela Bolaños”. Terre des Hommes 2000/2001 (2001): 27-37.

Cabildo, Taitas y Comisión de Trabajo del Pueblo Guambiano. Diagnóstico y plan de vida del Pueblo Guambiano. Territorio Guambiano-Silvia: Cabildo de Guambía/CENCOA/ Corporación Autónoma Regional del Cauca/Visión Mundial Internacional, 1994.

Camacho Azurduy, Carlos A. Las radios populares en la construcción de la ciudadanía: enseñanzas de la experiencia de ERBOL en Bolivia. La Paz: Universidad Andina Simón Bolívar, 2001.

Comunidad Camëntsá. Procesos de transformación y alternativas de autogestión indígena. Bogotá: ABC, 1989.

Condori Chura, Leandro y Estéban Ticona Alejo. El escribano de los caciques apoderadosKasikinakan purirarunakan qillqiripa. La Paz: Hisbol/THOA, 1992.

Correa Rubio, François. “Lo ‘indígena’ ante el Estado colombiano: reflejo jurídico de su conceptualización política”. Antropología jurídica: normas formales, costumbres legales en Colombia. Esther Sánchez, ed. Bogotá: Comité Internacional para el Desarrollo de los Pueblos/Sociedad Antropólogica de Colombia, 1992. 71-101.

Correa Rubio, François. “A manera de epílogo: derechos étnicos: derechos humanos”, en Encrucijadas de Colombia amerindia. François Correa, ed. Bogotá: Instituto Colombiano de Antropología/Colcultura, 1993. 319-34.

Cotacachi, Mercedes y Ruth Moya. Huaca pachamanta causashca rimai/Los cuentos de cuando las huacas vivían. Cuenca: Universidad de Cuenca, Licenciatura en Lingüística Andina y Educación Bilingüe, 1993.

CRIC (Consejo Regional Indígena del Cauca). “Elaboración de currículo en comunidades indígenas paeces”. Popayán: PEB-CRIC, 1990.

CRIC (Consejo Regional Indígena del Cauca). “Informe final, Profesionalización Consejo Regional Indígena del Cauca”. Popayán: PEB/CRIC, 2000.

Chatterjee, Partha. Nationalist Thought and the Colonial World: A Derivative Discourse. Minneapolis: University of Minnesota Press, 1986.

Choque, Roberto, Vitaliano Soria, Humberto Mamani, Estéban Ticona y Ramón Conde. Educación indígena: ¿ciudadanía o colonización? La Paz: THOA, s.f.

Chow, Rey. Primitive Passions: Visuality, Sexuality, Ethnography, and Contemporary Chinese Cinema. New York: Columbia University Press, 1995.

Dagua Hurtado, Abelino, Misael Aranda y Luis Guillermo Vasco. Guambianos: hijos del aroiris y del agua. Bogotá: CEREC/Los Cuatro Elementos/Fondo Promoción de la Cultura, Banco Popular/Fundación Alejandro Angel Escobar, 1998.

De La Cadena, Marisol. "The Political Tensions of Ethnic Representations and Misrepresentations: Intellectuals and Mestizas in Cuzco, 1919-1991”. Ponencia presentada en la reunión anual de la Latin American Studies Association, Washington, DC, septiembre, 1995.

Deleuze, Gilles y Felix Guattari. “What is a Minor Literature?” Mississippi Review 31 (Winter/Spring, 1983): 13-27.

Dover, Robert V.H. "Nucanchi Gente Pura”: The Ideology of Recuperación in the Inga Communities of Colombia's Sibundoy Valley. Tesis doctoral, Indiana University, Bloomington, Indiana, 1995. 
Escobar, Arturo. Encountering Development: the Making and Unmaking of the Third World. Princeton: Princeton University Press, 1995.

y Sonia Alvarez, eds. The Making of Social Movements in Latin America: Identity, Strategy, and Democracy. Boulder: Westview Press, 1992.

Espinosa, Myriam Amparo. El andar como metáfora territorial páez. Tesis de Maestría en Antropología Andina, FLACSO-Quito, 1995.

Farrington, John, Anthony Bebbington, Kate Wellard y David J. Lewis. Reluctant Partners? Non-Governmental Organizations, the State and Sustainable Agricultural Development. New York y Londres: Routledge, 1993.

Feierman, Steven. Peasant Intellectuals: Anthropology and History in Tanzania. Madison: University of Wisconsin Press, 1990.

Fernández O., Marcelo. La ley del ayllu: práctica de jach’a justicia y jisk’a justicia (justicia mayor y justicia menor) en comunidades aymaras. La Paz: PIEB, 2000.

Foucault, Michel. Power/Knowledge: Selected Interviews and Other Writings 19721977. Colin Gordon, ed. New York: Random House, 1977.

Gow, David D. "Can the Subaltern Plan? Ethnicity and Development in Cauca, Colombia”. Urban Anthropology 26/3-4 (1997): 243-292.

Gramsci, Antonio. Selections from the Prison Notebooks. New York: International Publishers, 1971.

Gros, Christian. "Derechos indígenas y nueva constitución en Colombia”. Análisis Político 19 (Bogotá, 1993): 8-24.

Políticas de la etnicidad: identidad, Estado y modernidad. Bogotá: Instituto Colombiano de Antropología e Historia, 2000.

Gruzinski, Serge. La colonisation de l'imaginaire: sociétés indigènes et occidentalisation dans le Mexique espagnol, XVIe-XVIIIe siécles. Paris: Gallimard, 1988.

Healey, Kevin. Llamas, Weavings and Organic Chocolate: Indigenous Grassroots Development Experiences from the Andes and Amazon of Bolivia. South Bend, Indiana: University of Notre Dame Press/Kellogg Institute for International Studies, 2000.

Inda C., Lorenzo. Historia de los urus comunidad Irohito Yanapata. La Paz: Hisbol/Radio San Gabriel, 1988.

Jackson, Jean. "Culture, Genuine and Spurious: The Politics of Indianness in the Vaupés, Colombia”. American Ethnologist 22/1 (1995): 3-27.

Jacoby, Russell. The Last Intellectuals: American Culture in the Age of Academe. New York: Basic, 1987.

Kowii, Ariruma. Mutsuctsurini. Quito: Corporación Editora Nacional, 1988.

León Trujillo, Jorge. De campesinos a ciudadanos diferentes. Quito: CEDIME/AbyaYala, 1994.

Lomnitz-Adler, Claudio. Exits from the Labyrinth: Culture and Ideology in the Mexican National Space. Berkeley y Los Angeles: University of California Press, 1992.

Luykx, Aurolyn. The Citizen Factory: Schooling and Cultural Production in Bolivia. Albany: SUNY Press, 1999.

Macas, Luis. "El levantamiento indígena visto por sus protagonistas”. Indios. Diego Cornejo Menacho, ed. Quito: ILDIS/Abya-Yala, 1991. 17-36. 
Mallon, Florencia. Peasant and Nation: The Making of Postcolonial Mexico and Peru. Berkeley y Los Angeles: University of California Press, 1995.

Mamani Condori, Carlos B. Taraqu, 1866-1935: masacre, guerra y “Renovación” en la biografía de Eduardo L. Nina Qhispi. La Paz: Ediciones Aruwiyiri, 1991.

Mamani Q., Alejandro. Historia y cultura de Cohana. La Paz: Hisbol/Radio San Gabriel, 1988.

Molina, Manuel J., Misael Aranda y José Manuel Tunubalá. Evaluación de la experiencia educativa guambiana (informe final). Informe presentado al Fondo de Becas de Investigación Francisco de Paula Santander (Colcultura), Guambía (Colombia): manuscrito, 1996.

Muelas Hurtado, Bárbara. "Relación espacio-tiempo en el pensamiento guambiano”. Proyecciones Lingüísticas 1/1 (Popayán, 1995): 31-40.

Nelson, Diane M. A Finger in the Wound: Body Politics in Quincentennial Guatemala. Berkeley y Los Angeles: University of California Press, 1999.

Pacari, Nina. "Levantamiento indígena”. Sismo étnico en el Ecuador. AA.VV. Quito: CEDIME, 1993. 169-86.

Pajuelo Teves, Ramón. “Fronteras, representaciones y movimientos étnicos en los países centroandinos en tiempos de globalización”. Producción Social de Representaciones de Identidades y Diferencias Sociales en Tiempos de Globalización. Daniel Mato, ed. Caracas: Universidad Central de Venezuela, 283-302.

Pratt, Mary Louise. “Arts of the Contact Zone”. Profession 91 (1991): 33-40.

Rafael, Vicente L. Contracting Colonialism: Translation and Christian Conversion in Tagalog Society under Early Spanish Rule. Durham: Duke University Press, 1993.

Ramón Valarezo, Galo. El regreso de los runas: la potencialidad del proyecto indio en el Ecuador contemporáneo. Quito: Comunidec/Fundación Interamericana, 1993.

Ramos, Abelardo, Graciela Bolaños, Susana Piñacué, Luz Mary Niquinás y Benjamín Ramos. "El area de comunicación y lenguaje en el proceso educativo del CRIC". Segundo Congreso Nacional Universitario de Etnoeducación. Popayán, julio de 2000.

Ramos, Abelardo y Cabildo Indígena de Mosoco. Ec ne'hwe's': Constitución política de Colombia en nasa yuwe. Bogotá: CCELA-UniAndes, 1993.

Rappaport, Joanne. The Politics of Memory: Native Historical Interpretation in the Colombian Andes. Cambridge: Cambridge University Press, 1990.

“Hacia la construcción de una historia propia”. C’ayu’ce 4 (Popayán, 2000): 1013.

"El espacio del diálogo pluralista: historia del Programa de Educación Bilingüe”. Producción Social de Representaciones de Identidades y Diferencias Sociales en Tiempos de Globalización. Daniel Mato, ed. Caracas: Universidad Central de Venezuela, 2003. 257-282.

"Redrawing the Nation: Indigenous Intellectuals and Ethnic Pluralism in Colombia". After Spanish Rule: Rethinking History and "The Postcolonial" in the Americas. en Mark Thurner and Andrés Guerrero, eds. Durham: Duke University Press, 2003. 31046. 
ed. Retornando la mirada: una investigación colaborativa interétnica sobre el Cauca a la entrada del milenio. Popayán: Editorial Universidad del Cauca, 2005. Intercultural Utopias: Public Intellectuals, Cultural Experimentation, and Ethnic Dialogue in Colombia. Durham: Duke University Press, 2005.

y David D. Gow. "Cambio dirigido, movimiento indígena y estereotipos del indio: el Estado colombiano y la reubicación de los nasa”. Antropología en la modernidad. María Victoria Uribe y Eduardo Restrepo, eds. Bogotá: Instituto Colombiano de Antropología, 1997. 361-99.

Rivera Cusicanqui, Silvia. "Oprimidos pero no vencidos": luchas del campesinado aymara y qhechwa, 1900-1980. La Paz: Hisbol, 1986.

Rojas, José María. “Intelectuales, campesinos e indios”, ponencia presentada en el XIX Congreso Latinoamericano de Sociologia, Caracas, mayo-junio, 1993.

Rojas Curieux, Tulio. "La traducción de la Constitución de la República de Colombia a lenguas indígenas”. “Del olvido surgimos para traer nuevas esperanzas”-la jurisdicción especial indígena. República de Colombia, Dirección General de Asuntos Indígenas, ed. Bogotá: Ministerio de Justicia y del Derecho/Ministerio del Interior, 1997. 229-244.

Sisco, Manuel. Despertary uso de la palabra tradicional. Trabajo realizado en Tierradentro1994/1999. Popayán: CRIC (en preparación).

Spivak, Gayatri. “Subaltern Talk: Interview with the Editors”. The Spivak Reader. Donna Landry y Gerald MacLean, eds. New York y Londres: Routledge, 1996. 287-308.

Stephenson, Marcia. "Forging an Indigenous Counterpublic Sphere: The Taller de Historia Oral Andina in Bolivia”. Latin American Research Review 37/2 (2002): 99118.

Thomas, Nicolas. Entangled Objects: Exchange, Material Culture, and Colonialism. Cambridge: Harvard University Press, 1991.

Ticona Alejo, Esteban. Organización y liderazgo aymara, 1979-1996. La Paz: Universidad de la Cordillera/Cochabamba: AGRUCO, Agroecología Universidad Cochabamba, 2000.

Ticona A., Estéban, Gonzalo Rojas O. y Xavier Albó C. Votos y wiphalas: campesinos y pueblos originarios en democracia. La Paz: Fundación Milenio/ CIPCA, 1995.

Van Cott, Donna Lee. The Friendly Liquidation of the Past: The Politics of Diversity in Latin America. Pittsburgh: University of Pittsburgh Press, 2000.

Vasco Uribes, Luis Guillermo, Abelino Dagua Hurtado y Misael Aranda. “En el segundo día, la Gente Grande (Numisak) sembró la autoridad y las plantas y, con su jugo, bebió el sentido”. Encrucijadas de Colombia amerindia. François Correa, ed. Bogotá: Instituto Colombiano de Antropología, 1993. 9-48.

Warren, Kay B. Indigenous Movements and their Critics: Pan-Maya Activism in Guatemala. Princeton: Princeton University Press, 1998.

Yashar, Deborah. "Democracy, Indigenous Movements, and the Postliberal Challenge in Latin America”. World Politics 52/1 (1999): 76-104.

Yule Y., Marcos. “Avances en la investigación del Nasa Yuwe(lengua páez)”. Proyecciones Lingüísticas 1/1 (Popayán, 1995): 23-30. 
Zamosc Leon. The Agrarian Question and the Peasant Movement in Colombia: Struggles of the National Peasant Association, 1967-1981. Cambridge: Cambridge University Press and Geneva United Nations Research Institute for Social Development, 1986. 